\title{
Resveratrol reverses Doxorubicin resistance by inhibiting epithelial-mesenchymal transition (EMT) through modulating PTEN/ Akt signaling pathway in gastric cancer
}

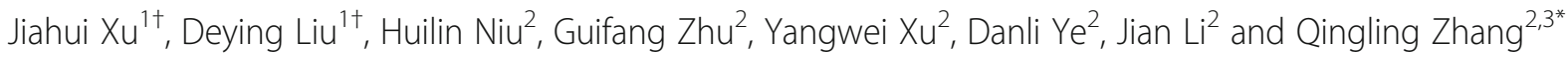

\begin{abstract}
Background: Gastric cancer is one of the major causes of cancer-related mortality worldwide. Most of patients presenting with inoperable gastric cancers rely on systemic chemotherapy for prolongation of survival. Doxorubicin (DOX) is one of the important agents against gastric cancer. Acquired DOX-resistance severely impedes the chemotherapeutic effect, invariably leading to poor prognosis. Resveratrol (RES) as a kind of phytoalexin has demonstrated anti-tumor functions in breast cancer and myeloid leukemia, but its function and mechanism are still unknown in gastric cancer treatment.

Methods: CCK8 assay was used to detect the cytotoxicity of DOX and RES to gastric cancer cells. DOX-resistant subclone cell line (SGC7901/DOX) was derived from SGC7901 cells exposed to stepwise increasing concentrations of DOX treatment. We measured the migratory capabilities of SGC7901/DOX cells by Cell scratch test and Transwell assay. SGC7901/DOX cells were treated with DOX, RES, neither or both. Then we analyzed cell survival by CCK8 assay, colony formation by Colony-forming assay, cell apoptosis by Annexin-V-FITC and PI dual staining assay and cell migration by Cell scratch test and Transwell assay. Western blotting was conducted to detect the protein expressions of PTEN/Akt signaling pathway and EMT-related markers. Immunofluorescence was performed to confirm the EMT-related markers expressions. The xenograft model was used to assess the effect of DOX and RES in vivo. The key molecules associated with proliferation, apoptosis and EMT were evaluated by immunohistochemistry in tumor specimens.
\end{abstract}

Results: SGC7901/DOX cells acquired drug resistance and enhancive migratory capability. RES enabled SGC7901/ DOX cells to regain DOX sensitivity, mitigated the aggressive biological features, promoted cell apoptosis in vitro and inhibited tumor growth in vivo. Mechanistic studies revealed that SGC7901/DOX cells underwent epithelialmesenchymal transition (EMT) which was induced by Akt activation, and through activating PTEN, RES inhibited the Akt pathway, and then achieved the reversion of EMT.

Conclusion: RES serves as a novel solution to reverse the DOX-resistance of gastric cancer via preventing EMT by modulating PTEN/Akt signaling pathway. DOX-RES combined treatment provides a promising future for gastric cancer patients to postpone drug resistance and prolong survival.

Keywords: Resveratrol, Doxorubicin, Drug resistance, EMT, PTEN/Akt

\footnotetext{
*Correspondence: zqllc8@126.com

${ }^{\dagger}$ Equal contributors

${ }^{2}$ Department of Pathology, School of Basic Medical Sciences, Southern

Medical University, Guangzhou 510515, China

${ }^{3}$ Department of Pathology, Nanfang Hospital, Southern Medical University,

Guangzhou 510515, China

Full list of author information is available at the end of the article
} 


\section{Background}

Gastric cancer is the fourth common malignancy in males and the fifth in females. It accounts for about 9\% of worldwide cancer deaths in 2012 [1]. Most newly diagnosed cases present with locally advanced or metastatic gastric cancers [2, 3] Still those patients with operable gastric adenocarcinoma would have a high risk of recurrence after tumor complete resection despite improvements in the surgical treatment [4]. Chemotherapy has long been considered as a sophisticated treatment of locally advanced and metastatic gastric cancers $[5,6]$. Doxorubicin (DOX), an anthracycline-based anti-tumor drug combined with other chemotherapeutic agents including fluorouracil and mitomycin, was first introduced as a gold therapy regimen for advanced gastric cancer patients in 1980 [7]. However, some clinical trials reported traditional DOX-based regimens failed to prolong survival and brought about some adverse effects for gastric cancer patients [8-11]. Recent in vitro study indicated that the frequent acquisition of DOX resistance and the potential induction of epithelial-mesenchymal transition (EMT) might be crucial in the limitation of DOX treatment in gastric cancer [12]. To find out a novel solution to alleviate the adverse effects in an all-round way, we endeavor to discover a chemo-sensitizer and side-effects attenuator for DOX in gastric cancer chemotherapy as well as its molecular mechanism.

A number of phytochemicals available exhibit chemopreventive effect and sensitize cancer cells toward DOX [13]. Among various phytochemicals, resveratrol (RES), a self-protective polyphenolic phytoalexin derived from plants, has attracted increasing attention due to its multiple health benefits [14]. In addition to the pharmacological effects of RES on the aging process, diabetes, neurological dysfunction, cardiovascular system and inflammation, its potent anti-tumor activity were closely observed in studies including breast cancer, lung cancer, prostate cancer, hepatocaracinoma, colorectal cancer and so on [14-16]. The combined treatment of DOX and RES achieves a synergistic effect and reverses multidrugresistance in breast cancer cells [17] and acute myeloid cells [18]. As DOX is one of the key chemotherapy agents in gastric cancer treatment, the combination of DOX and RES turns out to be a potentially promising chemotherapy regimen for gastric cancer and the relevant mechanism remains to be explored.

In this study, DOX-resistant human gastric cancer cell line (SGC7901/DOX) was established and demonstrated aggressive migratory capabilities. Then RES was introduced and it successfully alleviated cell migration and chemo-sensitized DOX through reversing EMT process and regulating PTEN and Akt/mTOR pathway. Our work sheds new light on RES as a potential adjuvant to DOX in gastric cancer treatment to solve drug resistance and tumor metastasis. And the relevant mechanism study and prospective clinical trials are expected.

\section{Methods \\ Cell culture}

Human gastric cancer cells SGC7901 and MGC803 were obtained from American Type Culture Collection Cell Biology Collection (ATCC, Manassas, VA, USA) and maintained in Department of Pathology, Southern Medical University (Guangzhou, China). Cells were cultured in RPMI 1640 medium supplemented with 10\% fetal bovine serum (FBS) at $37{ }^{\circ} \mathrm{C}$ in a humidified incubator containing $5 \% \mathrm{CO}_{2}$.

\section{Establishment of DOX-resistant gastric cancer cell line}

The DOX concentration gradient progressive increase induction method was used to develop DOX-resistant phenotype SGC7901 cell line. SGC7901 cells at a concentration of $1 \times 10^{5} / \mathrm{ml}$ were inoculated in DOX-free culture medium for $24 \mathrm{~h}$ until they got in the logarithmic phase. Then the culture medium was replaced with that containing low concentration $(0.125 \mathrm{mg} / \mathrm{L})$ DOX (Nanfang Hospital, Guangzhou, China, dissolved in RPMI 1640 medium) for $48 \mathrm{~h}$. Then the culture medium containing drugs and dead cells was discarded. Cells were collected and re-inoculated in DOX-free culture medium to get recovered before next DOX treatment. After cells got adjusted to present DOX treatment, we increased the concentration of DOX and repeated the DOX and DOX-free treatment in turn until cells survived well and developed resistance to $0.75 \mathrm{mg} / \mathrm{L}$ DOX treatment. We referred to this DOX-resistant SGC7901 cell line as SGC7901/DOX. Both DOX- sensitive SGC7901 and DOX-resistant SGC7901/DOX were cultured under the same conditions and in drug-free medium for 2 days before commencing the experiments.

\section{CCK-8 assay}

Cell survival rates were estimated by the CCK-8 assay (keyGEN biotech, Jiangsu, China). Approximately $10^{4}$ cells were seeded in 96-well plates with $100 \mu \mathrm{l}$ medium each well. After $24 \mathrm{~h}$ cultivation, different doses of DOX or/and RES were added respectively. Each well was incubated with $10 \mu \mathrm{g}$ CCK-8 solution for $2 \mathrm{~h}$ away from light before measuring the absorbance at $450 \mathrm{~nm}$ by PerkinElmer's EnSpire Multilabel Plate Reader.

\section{Cell scratch test}

When the cells seeded in 6-well plate reached a confluent state, a single scratch was made using a sterile $10 \mu$ pipette tip. The cells were then incubated with FBS-free culture medium (to exclude the potential effects of FBS on cell migration) alone or containing different concentrations of DOX or RES (SinaBestBio, 
Shanghai, China, dissolved in 10\% DMSO (DMSO:RPMI 1640 medium =1:9)). Images of the scratches were captured at 0, 24 and $48 \mathrm{~h}$ with Olympus IX71 inverted microscope at $100 \times$ magnification. The width of the scratch was analyzed using the Olympus CellSens Dimension software.

\section{Transwell migration assay}

Transwell migration assay was performed using transwell inserts (BD bioscience, SanJose, CA) with a filter of $8 \mu \mathrm{m}$ pore. Cells were left untreated or treated with DOX, RES or both for 48 h. $8 \times 10^{4}$ cells in serum-free medium were seeded into the upper chamber of the insert and complete medium was added to the lower chamber. After $36 \mathrm{~h}$ incubation, the cells were fixed with methanol and stained with Giemsa. Then cells on the top surface of the membrane were wiped off, and cells on the lower surface were examined with Olympus DP72 microscope at 100× magnification. 4 random fields were photographed for counting purposes and the average number of migrated cells was used as a measure of migration capacity.

\section{Colony-forming assay}

Cells were left untreated or treated with DOX, RES or both for $48 \mathrm{~h}$. Then cells were trypsinized and dispensed into individual wells of six-well tissue culture dishes with a density of 300 cells per well. Following another 14 days in drug-free culture, cells were fixed and stained with Giemsa to visualize colonies. Experiments were performed in triplicate.

\section{Apoptosis analysis}

To detect cell apoptosis, cells were incubated with DOX or RES at different concentrations for $24 \mathrm{~h}$. About $1 \times 10^{5}$ cells were harvested by EDTA-free trypsinization and washed twice with cold PBS. After being resuspended in $500 \mu \mathrm{L}$ binding buffer, cells were stained with $5 \mu \mathrm{L}$ Annexin-V-FITC and $5 \mu \mathrm{L}$ PI (Keygen bioTECH, Jiangsu, China) in dark condition at room temperature for $15 \mathrm{~min}$. Lastly, cell apoptosis was measured by FACSAria flow cytometer (BD, USA).

\section{Immunofluorescence}

The cells seeded in co focal dishes were fixed with $4 \%$ paraformaldehyde and then kept stable in $0.2 \%$ Triton for $10 \mathrm{~min}$ to rupture the cell membranes. Following three PBS washing, non-specific antigen-binding sites were blocked by $2 \%$ BSA for $30 \mathrm{~min}$. The cells were then incubated with anti- Vimentin, E-cadherin (Abcam, 1:200); anti- $\beta$-catenin (Proteintech, 1:50) overnight at $4{ }^{\circ} \mathrm{C}$. After washing, cells were incubated with anti-rabbit antibody for $60 \mathrm{~min}$ and the nuclei were stained with DAPI for 2 min, which was washed with PBS later. Cells were kept from light before observed with a fluorescence microscope.

\section{Western blot analysis}

Cells to be tested were homogenized in Lysis Buffer (containing $0.1 \%$ protease inhibitor, $0.5 \% 100 \mathrm{mM}$ PMSF and $1 \%$ phosphatase inhibitor) and centrifuged at 12,000 rpm for $15 \mathrm{~min}$ at $4{ }^{\circ} \mathrm{C}$. The supernatant was collected and the total protein content was determined by BCA assay. Equal proteins $(40 \mu \mathrm{g} / \mathrm{lane})$ were loaded on SDS-PAGE gels and then transferred to $0.22 \mu \mathrm{m}$ PVDF membranes. Membranes were blocked with $5 \%$ fat-free milk (5\% skimmed milk powder in PBST, 0.1\% Tween in PBS) and incubated with primary antibodies overnight at $4{ }^{\circ} \mathrm{C}$. After being washed by PBST for $5 \times 5 \mathrm{~min}$, membranes were incubated with secondary antibodies for $1 \mathrm{~h}$ at room temperature. Following washing, target bands were visualized using Tanon-5200 Image Analyzer.

Primary antibodies used included rabbit monoclonal antibodies anti- PTEN, Akt, phosphor-Akt, mTOR, phosphor-mTOR, TSC1, TSC2, p70S6K, $\beta$-catenin, cleaved caspase-3 and caspase-9 (1:500, Cell Signaling Technology, Danvers, MA); rabbit monoclonal antibodies anti- Vimentin, E-cadherin (1:500, Abcam, Cambridge, UK); mouse monoclonal antibody anti-GAPDH (1:500, Proteintech, Chicago, IL). Protein bands were quantified using the Tanon-5200 Image Analyzer. All bands were normalized to GAPDH and the fold changes were calculated through relative quantification to the control group.

\section{Nude mice xenograft model}

Nude mice were purchased from Guangdong Medical Laboratory Animal Center (Guangzhou, China) and housed under controlled temperature $\left(28{ }^{\circ} \mathrm{C}\right)$ and pathogen-free conditions at Guangdong Provincial Key Laboratory of Molecular Tumor Pathology. All procedures were performed aseptically in accordance with the institutional guidelines of Guangdong Province and approved by the Experimental Animal Ethics Committee of Southern Medical University. $1 \times 10^{7}$ SGC7901/ DOX cells were injected subcutaneously into the left inguinal region of each nude mouse when the mice got five weeks old. Two weeks later, mice were randomly divided into four groups ( $n=5,3$ males, 2 females): Group 1 Control; Group 2 DOX (3 mg/kg); Group 3 RES (50 mg/kg); Group 4DOX (3 mg/kg) and RES $(50 \mathrm{mg} / \mathrm{kg})$. DOX was diluted in sodium chloride injection and given intraperitoneally (i.p.) while RES was dissolved in $10 \%$ DMSO and administered by gavage. Both drugs were given once a week for 4 consecutive weeks. The tumor volume $(\mathrm{V})$ was determined by measuring the length (a) and width (b) with calipers every week and calculated using the formula: $\mathrm{V}\left(\mathrm{mm}^{3}\right)$ $=1 / 2^{*} \mathrm{ab}^{2}$. At the end of the treatment period, mice were sacrificed, and tumors were collected for immunochemical studies. 


\section{Immunohistochemistry}

The tumor tissue was fixed with $4 \%$ formalin and paraffin embedded before cutting it into $3 \mu \mathrm{m}$ thick sections. And the sections were routinely deparaffinized in xylene and rehydrated in an alcohol gradient. Next, tissue antigen was retrieved by heating in sodium citrate $(\mathrm{pH} 6.0)$ or Tris-EDTA solution ( $\mathrm{pH} \mathrm{8.0)}$ for $10 \mathrm{~min}$. Sections were then blocked with $3 \% \mathrm{H} 2 \mathrm{O} 2$ before incubation with anti- caspase-3 (Cell Signaling Technology, 1:200); antiki67 (Cell Signaling Technology, 1:400); anti- Vimentin (Abcam, 1:500); anti-PTEN (Proteintech, 1:200) at $4{ }^{\circ} \mathrm{C}$ overnight. After three washes in PBS, the sections were incubated with secondary antibody (ZSGB-BIO, Beijing, China) for $30 \mathrm{~min}$ at room temperature. DAB kit (ZSGBBIO, Beijing, China) was sequentially applied to stain the slides. Following counter-staining in hematoxylin and mounting with neutral balsam, the tissue sections were observed using Olympus BX-UCB light-field microscope. 5 random fields at $\times 400$ magnification were captured for intensity analysis.

We used Image-Pro Plus software for semi-quantitative Image analysis. Firstly, we opened the image in the software and calibrated the optical density. In Measure menu we clicked Count/Size and chose Manual to enter into Segmentation dialogue box where the area of interest was set through: hue, $0 \sim 30$; saturation, $0 \sim 255$; intensity, $0 \sim 255$, then the image was converted to gray scale image. Subsequently, we returned to Count/Size window, clicked Count and the values were measured. The parameters included area sum and IOD. The mean optical density was calculated by IOD/area and designated as representative staining intensity $[19,20]$.

\section{Statistical analysis}

Data were expressed as means \pm SD of at least three independent experiments. Statistical evaluation of the data was performed by using the unpaired Student's $t$-test and ANOVA followed by a post-hoc test. Differences were considered to be statistically significant for $p<$ 0.05. Statistical analysis was performed by SPSS 19.0 software.

\section{Results}

\section{The effects of DOX and RES on gastric cancer cells}

We detected the chemo-sensibility of SGC7901 and MGC803 to DOX and RES treatment via CCK8 assay. The DOX concentration gradient ranges from $0.5 \mathrm{mg} / \mathrm{L}$ to $10 \mathrm{mg} / \mathrm{L}$. Results showed SGC7901 cell survival was inhibited by DOX and the inhibition rate was increased with DOX treatment time and concentration. However, DOX did not suppress MGC803 cell survival in a dose and time-dependent way until its concentration was over $2 \mathrm{mg} / \mathrm{L}$. Particularly, MGC803 survival rate could reach as high as $40 \%$ after 7 -day treatment of $0.5 \mathrm{mg} / \mathrm{L} \mathrm{DOX}$
(Fig. 1a). The RES concentration gradient ranges from $10 \mathrm{mg} / \mathrm{L}$ to $200 \mathrm{mg} / \mathrm{L}$. Results showed that RES also significantly inhibited SGC7901 cell survival dose and time-dependently within the concentration range set. However, RES did not suppress MGC803 cell survival in a dose and time-dependent way until its concentration was over $20 \mathrm{mg} / \mathrm{L}$ (Fig. 1b). The 7-day survival of MGC803 maintained over $80 \%$ when treated with $10 \mathrm{mg} / \mathrm{L}$ RES and about $60 \%$ in $20 \mathrm{mg} / \mathrm{L}$ RES.

\section{Drug-resistant SGC7901/DOX cells were established and demonstrated enhancive migratory phenotype}

Overall, DOX and RES demonstrated similar effects on the survival of both gastric cancer cell lines. But compared with MGC803, SGC7901 was more sensitive to both drugs, which made it a proper subject of our further study. The half maximal inhibitory concentration (IC50) of DOX in day2 for SGC7901 was $0.7635 \mathrm{mg} / \mathrm{L}$ (with $95 \%$ confidential interval 0.6765 to $0.8617 \mathrm{mg} / \mathrm{L})$.

DOX-resistant subclone cell line (SGC7901/DOX) was derived from SGC7901 cells exposed to stepwise increasing concentrations $(0.125 \mathrm{mg} / \mathrm{L}$ to $0.75 \mathrm{mg} / \mathrm{L})$ of DOX treatment. To verify the DOX-resistant difference between SGC7901 and SGC7901/DOX cells, we treated both cell lines with different concentrations of DOX for 2 days and then measured the half maximal inhibitory concentration (IC50). The IC50 of parental SGC7901 cell line was $0.7173 \mathrm{mg} / \mathrm{L}$, and its $95 \%$ confidential interval (CI) was 0.6415 to $0.8019 \mathrm{mg} / \mathrm{L}$ while that of SGC7901/ DOX cell line was $2.959 \mathrm{mg} / \mathrm{L}$ with a $95 \%$ CI ranging from 2.554 to $3.428 \mathrm{mg} / \mathrm{L}$. The results showed that SGC7901/ DOX cells were more DOX-resistant in comparison to its parental SGC7901 cells for its IC50 was 316\% greater than that of SGC7901 (Fig. 2a).

Cell migration was analyzed by cell scratch test and transwell assay. Cell scratch test confirmed the migration potential of SGC7901/DOX $(147.91 \pm 4.32 \mu \mathrm{m})$ cells was $44.27 \%$ greater than that of SGC7901 cells (102.52 $\pm 4.72 \mu \mathrm{m}, p<0.001$ ) (Fig. 2b). Transwell assay also reported SGC7901/DOX cells acquired enhancive cell migratory ability than parental SGC7901 cells, which was evidenced by increased number of trans-membrane migrating cells by $90.53 \%$ (700.40 \pm 22.38 SGC7901/ DOX cells compared with $367.60 \pm 5.07$ SGC7901 cells $(p<0.01)$ (Fig. 2c).

\section{SGC7901/DOX cells underwent EMT associated with Akt activation}

EMT has been illustrated as a critical regulator in cell migration and drug resistance. Morphological observation showed that the parental SGC7901 cells were generally round or oval, but most of SGC7901/DOX cells transformed into spindle shape (Fig. 3a). The expression of EMT associated markers was measured by western blot. 


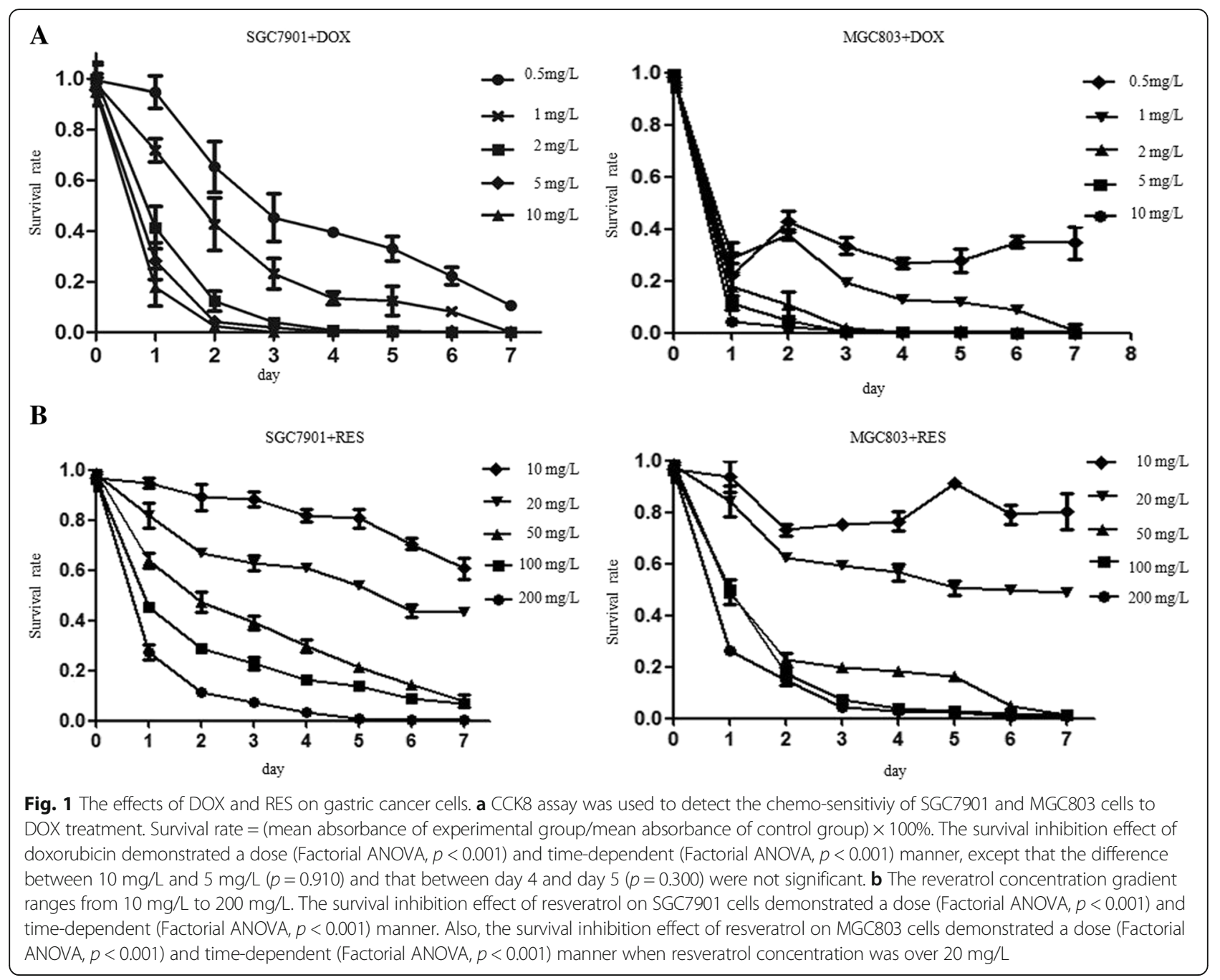

SGC7901/DOX cells were found to undergo EMT process for it expressed higher mesenchymal cell markers including $\beta$-catenin and vimentin while losing epithelial cell adhesion molecule such as E-cadherin. In addition, Akt was activated in SGC7901/DOX cells (Fig. 3b). EMT markers were also verified through immunofluorescent assay. Long-term DOX incubation decreased E-cadherin cytomembrane expression whereas increased vimentin expression in cytoplasm and enhanced $\beta$-catenin nuclear tranlocation (Fig. 3c).

\section{RES alleviated the aggressive phenotypes of SGC7901/ DOX cells}

To evaluate the cytotoxic effect of RES on SGC7901/DOX cells, cells were treated with $0.75 \mathrm{mg} / \mathrm{L}$ DOX or $50 \mathrm{mg} / \mathrm{L}$ RES, either alone or in combination. CCK8 assay results showed DOX $(0.75 \mathrm{mg} / \mathrm{L})$ had no significant effect on the survival of SGC7901/DOX cells, which indicated that SGC7901/DOX cells maintained DOX-resistant feature as previously described. As for the RES group, RES treatment displayed a time-dependent inhibitory effect on SGC7901/ DOX cell survival. Notably, when DOX was combined with RES, the survival rate of SGC7901/DOX cells was minimized (Fig. 4a).

Furthermore, we analyzed whether the combined treatment could suppress the colony-forming ability of SGC7901/DOX cells. DOX and RES treatment decreased the number of SGC7901/DOX cell colonies by only 33.95 and $76.54 \%$ respectively. When DOX and RES were combined, the colony forming ability of SGC7901/DOX cells reached the lowest point, much lower than either treatment alone (Fig. 4b).

Also, the effect of RES and/or DOX on cell apoptosis was measured. DOX treatment alone could induce SGC7901/DOX cell apoptosis, but it was not prominent at low concentrations $(1 \mathrm{mg} / \mathrm{L}$ and $1.5 \mathrm{mg} / \mathrm{L})$. RES alone triggered cell apoptosis in a concentration-dependent manner, with $8.7 \%$ apoptotic cells resulting in $50 \mathrm{mg} / \mathrm{L}$ treatment and then $26.5 \%$ in $100 \mathrm{mg} / \mathrm{L}$. Altogether, $1 \mathrm{mg} / \mathrm{L}$ DOX and $50 \mathrm{mg} / \mathrm{L}$ RES combined treatment 


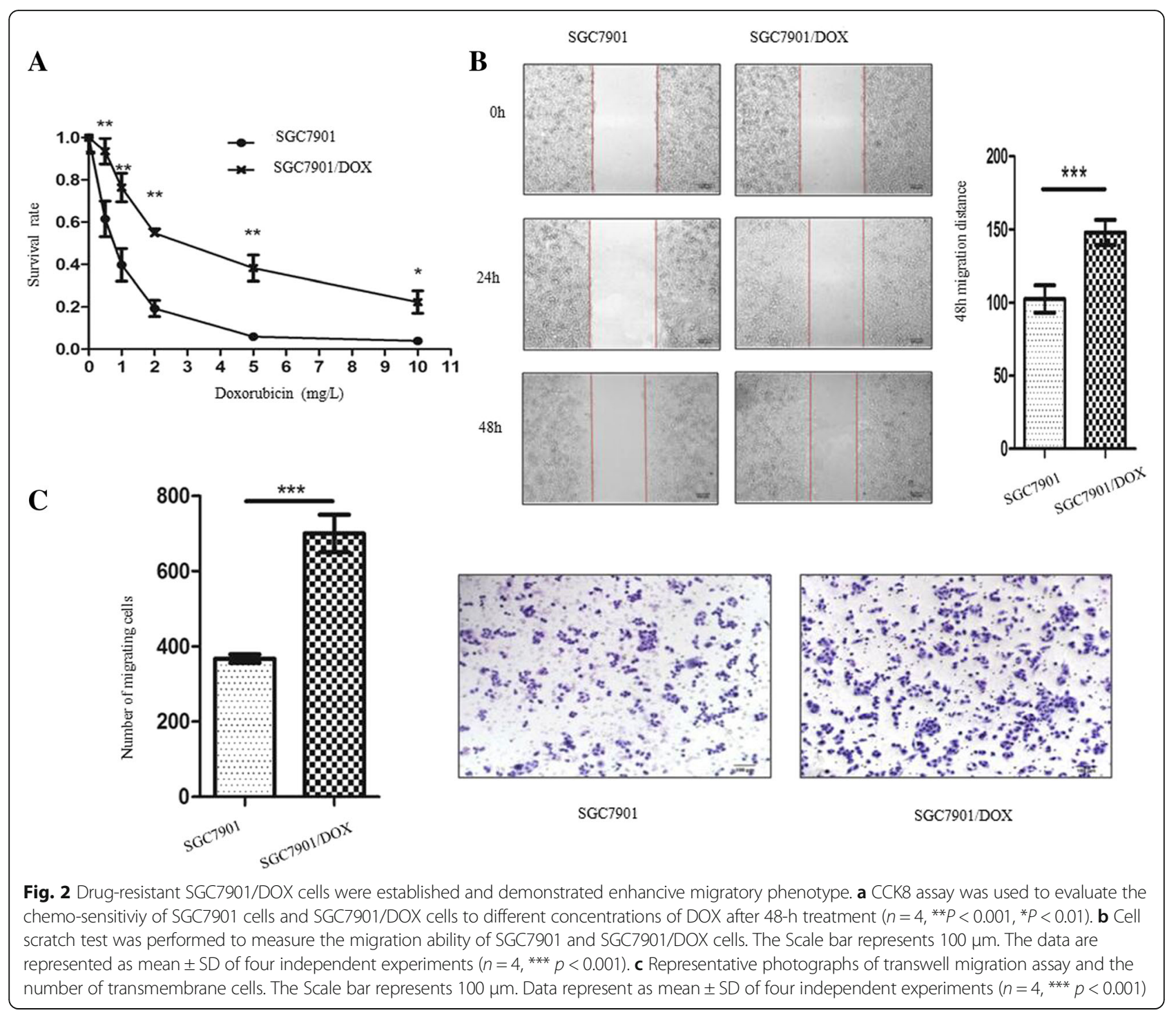

synergistically promoted cell apoptosis proportion up to 29.2\% (Fig. 4c). The results revealed that RES increased the DOX-sensibility of SGC7901/DOX cells by synergizing DOX's function in inhibiting cell proliferation and promoting cell apoptosis.

The effect of RES on SGC7901/DOX cell migration was also investigated. To our surprise, cell scratch test suggested that DOX treatment alone promoted the migration of SGC7901/DOX cells by $25.9 \%$ whereas RES decreased that of SGC7901/DOX by $53.13 \%$. Notably, combination of DOX and RES achieved a remarkably stronger migration-inhibitory effect than RES or DOX treatment alone (Fig. 4d). According to transwell assay results, after $48 \mathrm{~h}$ DOX treatment, the number of trans-membrane SGC7901/DOX cells was increased by $31.64 \%$. However, RES, whether alone or combined with DOX, drastically decreased migrating cell number (Fig. 4e). Therefore, RES effectively prohibited SGC7901/DOX cells migration and what's more, it significantly antagonized and reversed SGC7901/DOX cells migration when DOX was present.

\section{RES combined with DOX could reverse EMT}

To verify the migration-inhibitory effect of RES was associated with the mitigation or even reversion of EMT, morphological changes among SGC7901/DOX cells treated with DOX, RES or both for $48 \mathrm{~h}$ were captured. SGC7901/DOX cells, no matter treated with DOX or not, demonstrated spindle or shuttle shapes, but they turned round or oval when RES was present (Fig. 5a).

Then the expression of EMT-related proteins was detected by western blot and immunofluorescent assay for further verification. Similar to our previous findings in long-term DOX treated SGC7901/DOX cells, 48-h DOX treatment on SGC7901/DOX cells enhanced the 
$\mathbf{A}$
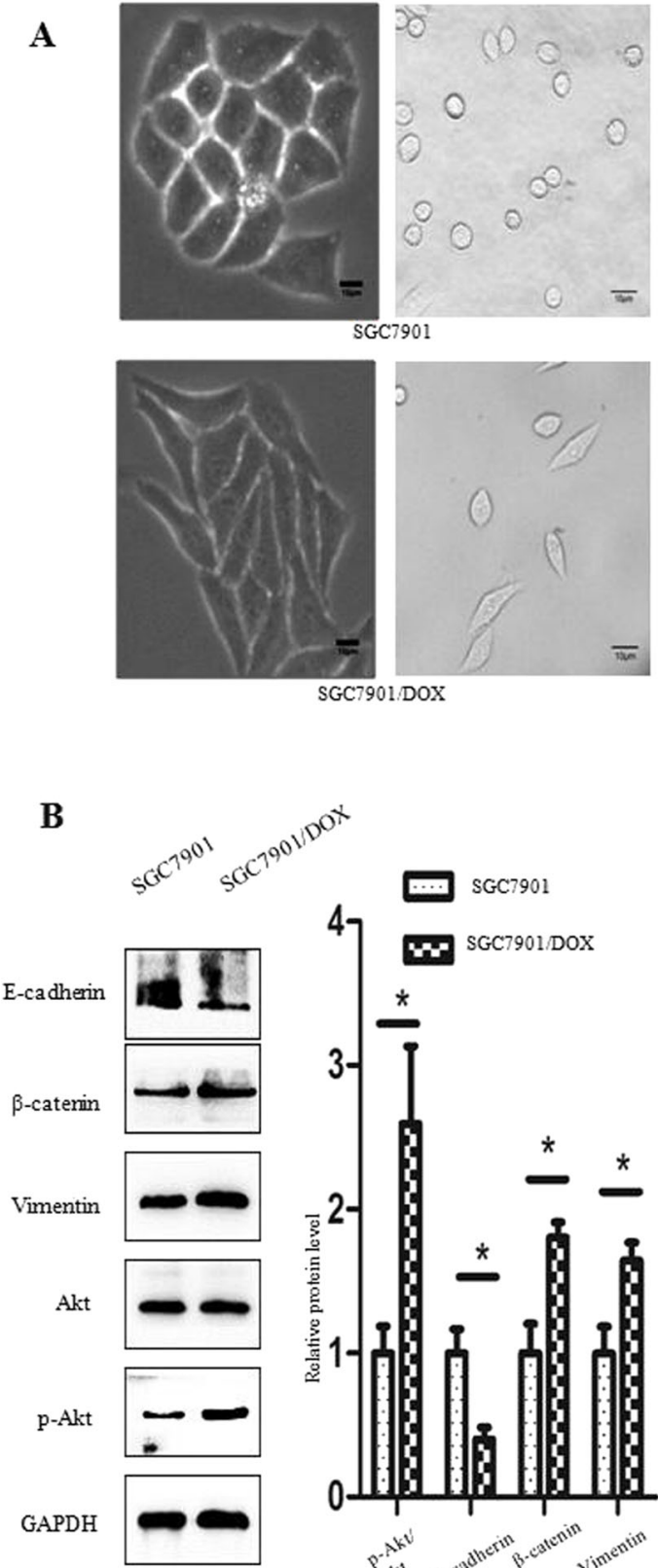

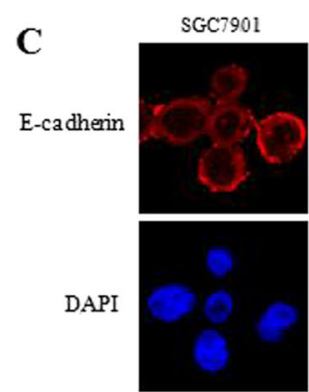

SGC7901/DOX
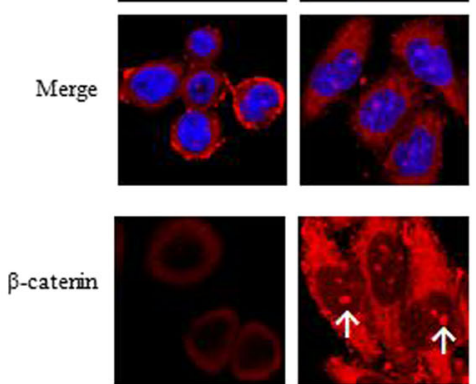

DAPI
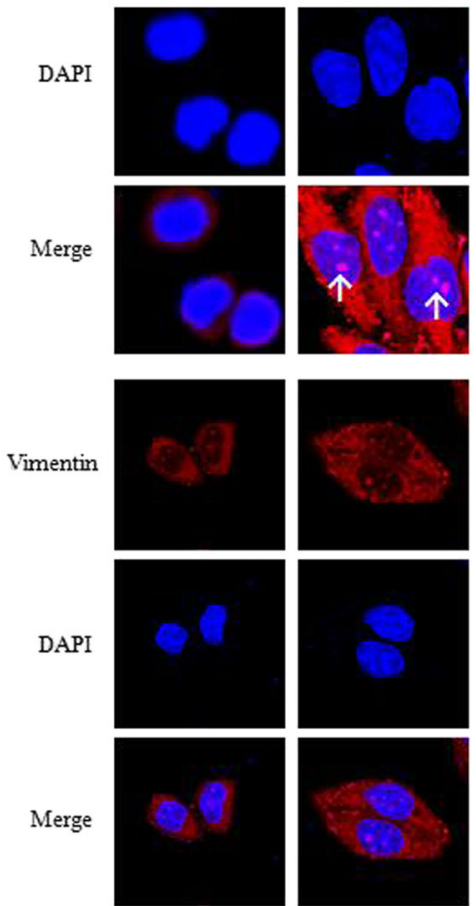

Fig. 3 SGC7901/DOX cells underwent EMT mediated by upregulation of Akt signaling pathway. a Images were captured by Olympus IX71 inverted microscope system. Morphological observation showed morphological variance between SGC7901/DOX and SGC7901 cells. The Scale bar represents $10 \mu \mathrm{m}$. b SGC7901 and SGC7901/DOX cells were left DOX-untreated for $48 \mathrm{~h}$ for Western blot assay, measeuring EMT-related proteins and Akt expression. Bar diagram shows the relative expressions of proteins normalized to GAPDH. Data are represented as mean \pm SD of three independent experiments $\left(n=3,{ }^{* * *} p<0.001 ;{ }^{* *} p<0.01 ;{ }^{*} p<0.05\right.$ : NS means not significant, $\left.p>0.05\right)$. c Immunofluorescence assay was used to detect EMT-associated proteins in SGC7901/DOX cells. E-cadherin, $\beta$-catenin, and vimentin were stained red and nuclei stained with DAPI were blue. The white arrow indicates $\beta$-catenin nuclear tranlocation. Images were captured at 1800× magnification

expression of mesenchymal cell markers such as vimentin and $\beta$-catenin, and reduced that of E-cadherin, an epithelial cell adhesion molecule. RES treatment, whether combined with DOX or not, decreased the expression of vimentin and increased E-cadherin expression dominantly, but had not significantly changed that of $\beta$-catenin when treated alone. However, when DOX was present, RES significantly antagonized DOX-induced upregulation 


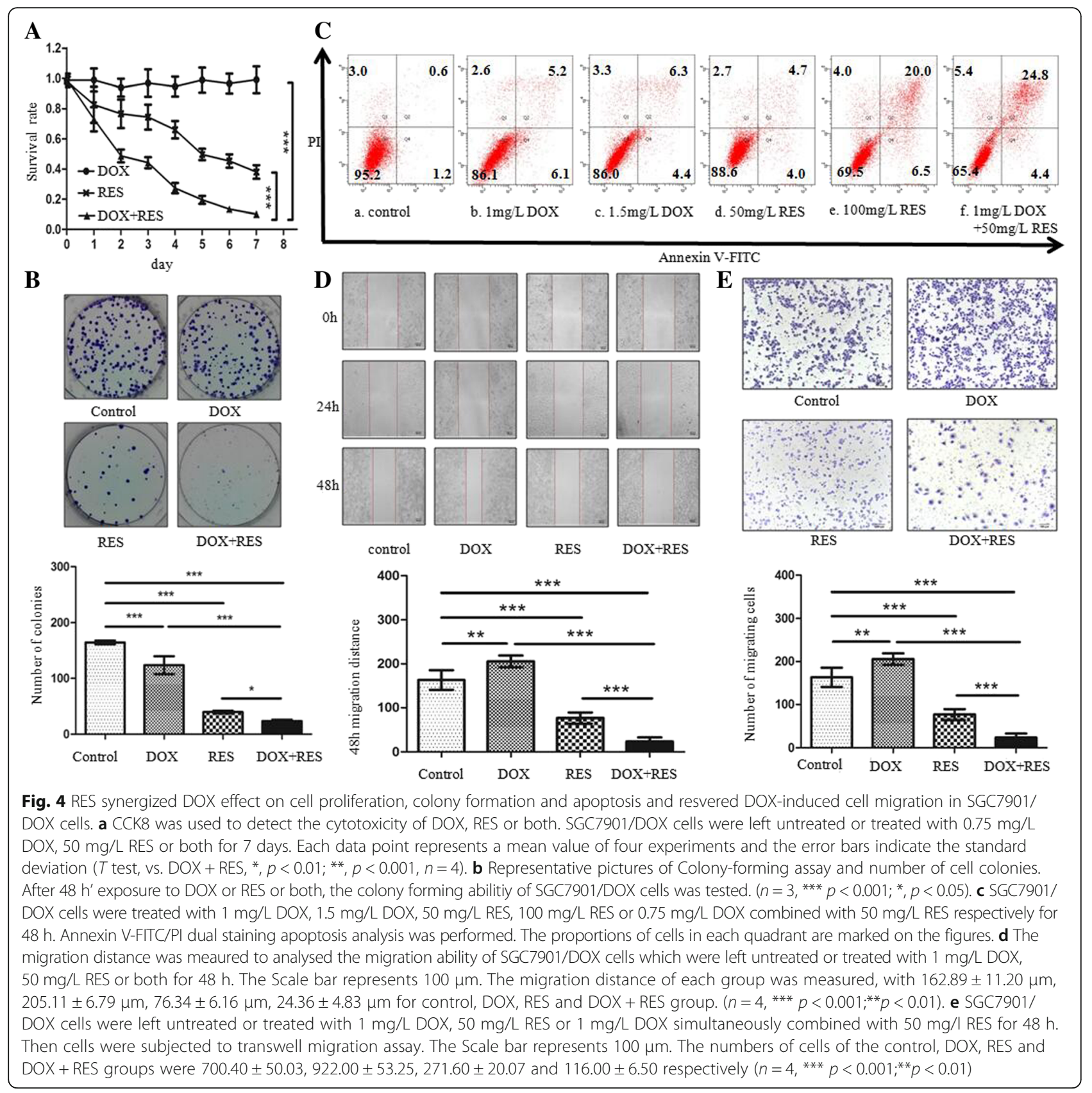

of $\beta$-catenin. And compared with either treatment alone, vimentin expression was significantly downregulated in DOX-RES combined treatment cells (Fig. 5b), which was consistent with its cell migration suppressing effect. Moreover, the downregulation of vimentin expression on combined treatment cells was intensified as RES concentration increased (Fig. 5c). Similar cellular changes of E-cadherin, $\beta$-catenin and vimentin expression were verified in immunofluorescent assay (Fig. 5d). These studies showed that RES antagonized DOX-induced EMT through the downregulation of vimentin and $\beta$-catenin, and upregulation of E-cadherin.

\section{RES modulated PTEN/Akt signaling pathway in SGC7901/ DOX cells}

To gain insight into the molecular mechanism through which RES reversed EMT, the expression of PTEN/Akt signaling pathway was analyzed by western blot. Results indicated that $1 \mathrm{mg} / \mathrm{L}$ DOX treatment alone did not affect PTEN expression significantly. Along with the combination of $1 \mathrm{mg} / \mathrm{L}$ DOX, however, RES significantly activated PTEN expression and prohibited Akt phosphorylation as its concentration increased from $20 \mathrm{mg} / \mathrm{L}$ to $200 \mathrm{mg} / \mathrm{L}$. Moreover, the expression of cleaved caspase- 9 was also enhanced in a RES-dependent way when RES 
$\mathbf{A}$

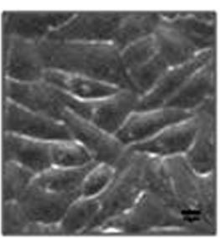

Control

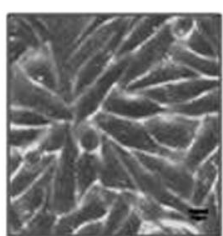

DOX

B

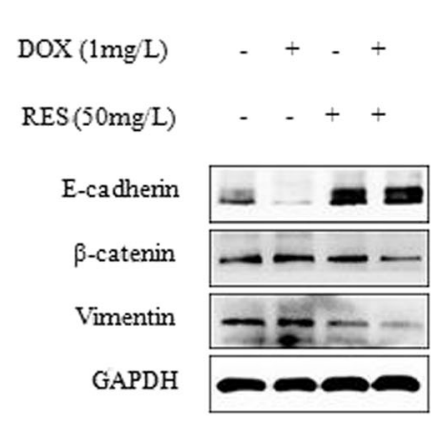

C

$\operatorname{DOX}(1 \mathrm{mg} / \mathrm{L})-++++++$

$\operatorname{RES}(\mathrm{mg} / \mathrm{L}) \quad-\quad 1020 \quad 50100200$
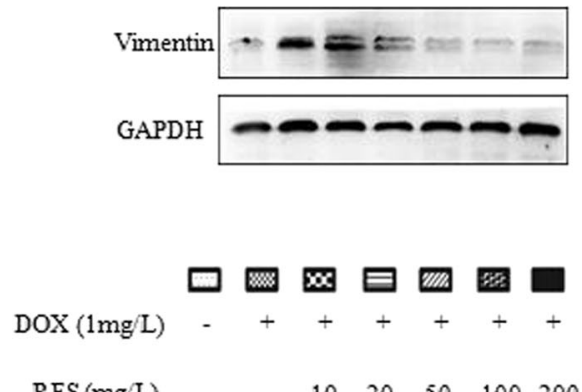

$\operatorname{RES}(\mathrm{mg} / \mathrm{L}) \quad$ - $\quad \begin{array}{lllll}10 & 20 & 50 & 100 & 200\end{array}$

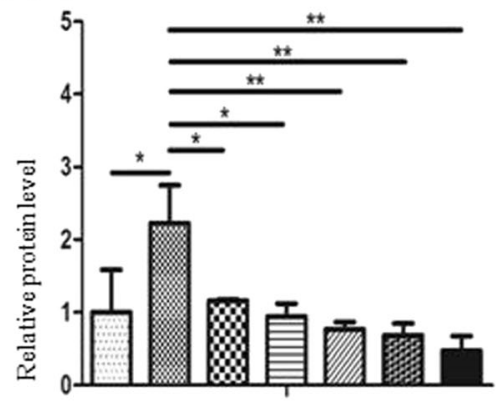

Vimentin
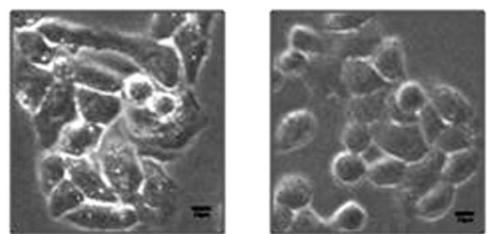

DOX+RES

四网曲

$\operatorname{DOX}(1 \mathrm{mg} / \mathrm{L})$ - + +

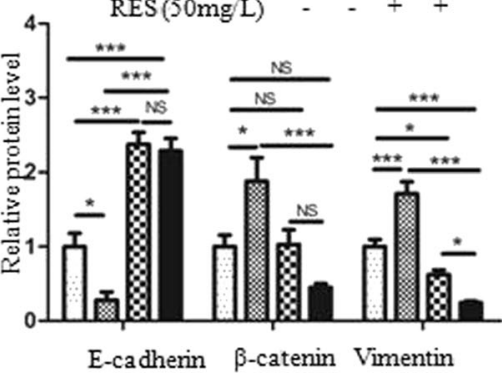

D

Control DOX

RES DOX+RES
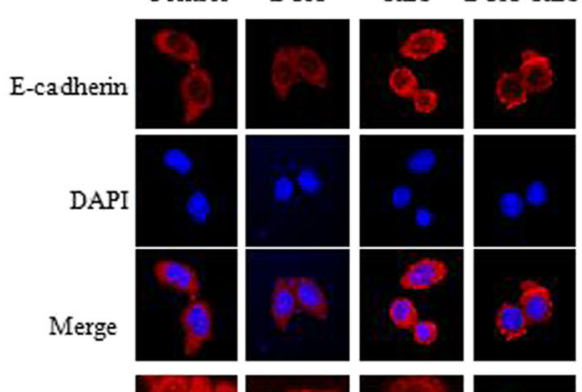

$\beta$-catenin
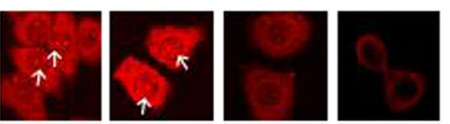

DAPI
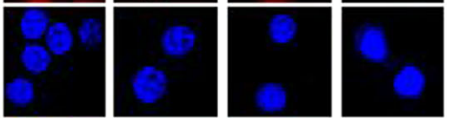

Merge
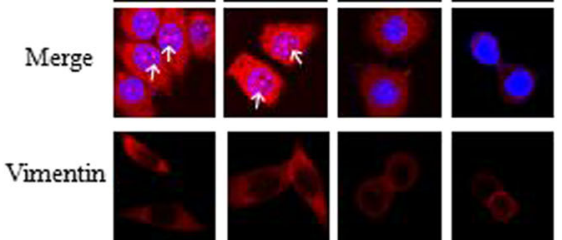

DAPI
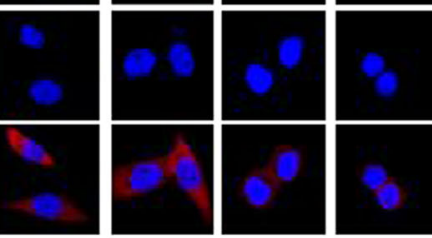

Fig. 5 Effect of RES on DOX-induced EMT. SGC7901/DOX cells were untreated or treated with 1 mg/l DOX, 50 mg/l RES or 1 mg/l DOX simultaneously combined with $50 \mathrm{mg} / \mathrm{I}$ RES for $48 \mathrm{~h}$. a Representative images of treated cells were shown. Scale bar represents $10 \mu \mathrm{m}$. b, c After $48 \mathrm{~h}$ treatment, cells were harvested for Western blot analysis to detect whether DOX and RES affect the expression of EMT-related proteins. Bar diagram shows the relative expressions of proteins normalized to GAPDH. Data are represented as mean \pm SD of three independent $\left(n=3,{ }^{* * *} p<0.001 ;{ }^{* *} p<0.01 ;{ }^{*} p<0.05\right.$ : NS means not significant, $p>0.05)$. $\mathbf{d}$ Immunofluorescence assay was used to detect EMT-related proteins. Vimentin, E-cadherin and $\beta$-catenin were stained red and nuclei stained with DAPI were blue. The white arrow indicates $\beta$-catenin nuclear tranlocation. Images were captured at 1800x magnification 
concentration ranged from $50 \mathrm{mg} / \mathrm{L}$ to $200 \mathrm{mg} / \mathrm{L}$ (Fig. 6a). To detect whether RES modulates PTEN/Akt signaling pathway as a whole, we treated SGC7901/DOX cells with $1 \mathrm{mg} / \mathrm{L}$ DOX, $50 \mathrm{mg} / \mathrm{L}$ RES or both. Consistant with previous observation, in $50 \mathrm{mg} / \mathrm{L}$ RES treatment group, we saw an significant increase in the level of PTEN, TSC1, TSC 2 and cleaved caspase- 3 and a reduction in p-Akt, p-mTOR and p70 S6K. Notably, when RES was combined with DOX, PTEN upregulation and caspase-3 cleavage were strengthened in comparison to RES treatment alone (Fig. 6b). This study verified that RES suppressed Akt signaling pathway by upregulating PTEN.
RES and DOX combination synergistically delayed tumor growth through reverse of EMT and promotion of apoptosis by activating PTEN in vivo

To evaluate the effect of DOX and RES on tumor growth, nude mice bearing subcutaneous SGC7901/DOX xenograpfts (with mean tumor volume $36.46 \pm 13.82 \mathrm{~mm}^{3}$ ) were given DOX, RES or both for 4 consecutive weeks. Administration of DOX $(3 \mathrm{mg} / \mathrm{kg})$ reduced the tumor volume by $50.44 \%$, from $1387.10 \pm 248.02 \mathrm{~mm}^{3}$ of Control to $687.45 \pm 69.69 \mathrm{~mm}^{3}(p<0.001)$, and RES $(50 \mathrm{mg} / \mathrm{kg})$ reduced the tumor volume by $58.42 \%$ to $576.80 \pm$ $110.64 \mathrm{~mm}^{3}(p<0.001)$. And likewise, the novel regimen of combinatorial treatment achieved a synergistic tumor-
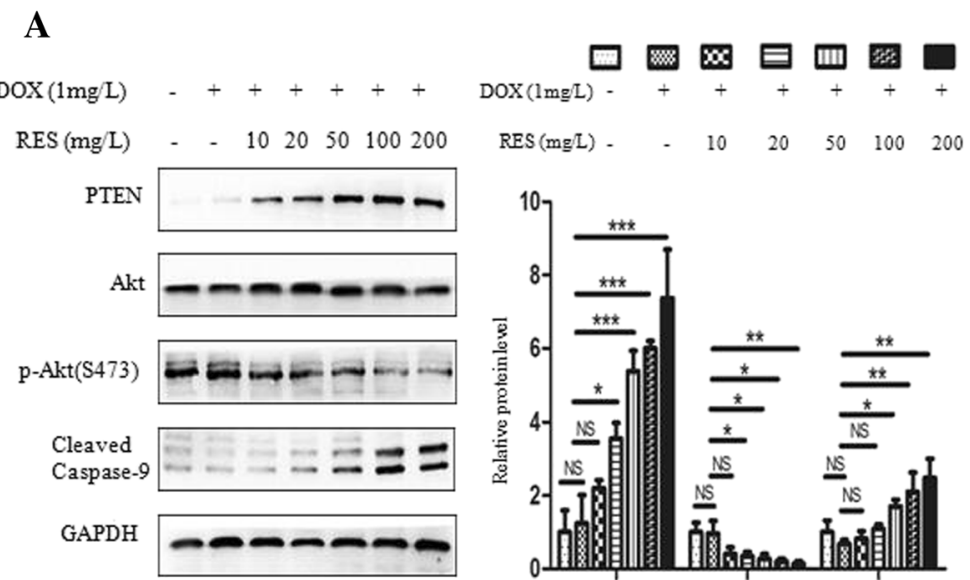

B

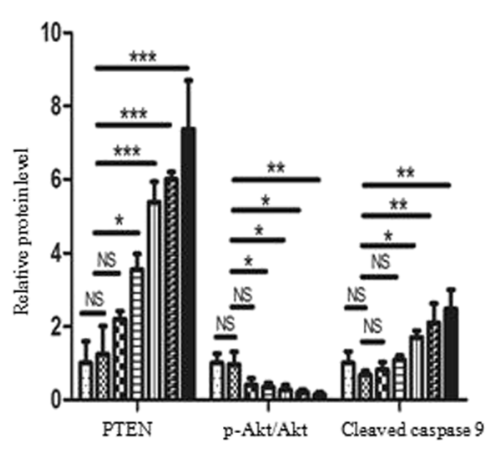

$\operatorname{DOX}(1 \mathrm{mg} / \mathrm{L}) \quad \ldots++$

$\operatorname{RES}(50 \mathrm{mg} / \mathrm{L}) \quad-\quad++$
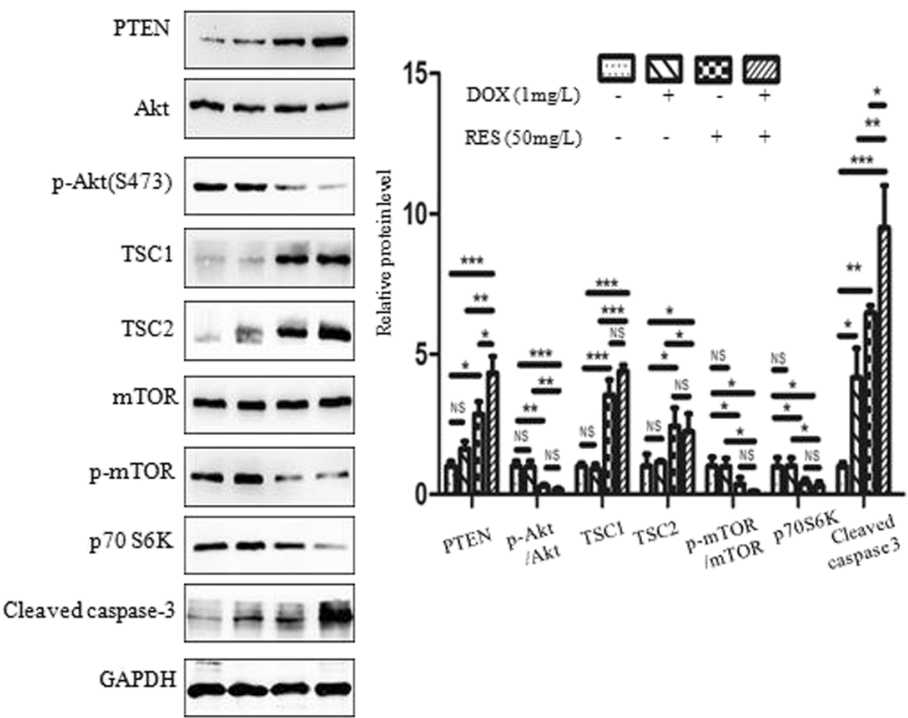

Fig. 6 Effect of RES on PTEN/Akt signaling pathway in SGC7901/DOX cells. a, b Following $48 \mathrm{~h}$ treatment, SGC7901/DOX cells were harvested for Western blot analysis to evaluate the effect of DOX and RES on PTEN/Akt signaling expression. Bar diagram shows the relative expressions of proteins normalized to GAPDH. Data are represented as mean \pm SD of three independent $\left(n=3,{ }^{* * *} p<0.001 ;{ }^{* *} p<0.01 ;{ }^{*} p<0.05\right.$ : NS means not significant, $p>0.05$ ) 
inhibitory effect, minimizing the tumor volume by $86.97 \%$ to $180.75 \pm 119.38 \mathrm{~mm}^{3}(p<0.001)$, which was $73.71 \%(p<0.001)$ and $68.66 \%(p<0.001)$ lower than DOX and RES treatment respectively (Fig. 7a).

To further validate the molecular basis, we then performed immunohischemistry on the tumor xenografts to detect the level of proliferation marker Ki67, EMT-related vimentin, apoptosis-related caspase 3 and the Akt signaling inhibitor PTEN in vivo. As expected, DOX alone did not affect PTEN expression, but significantly increased the expression of vimentin and caspase- 3 and reduced Ki67 expression. Compared with control group, RES alone evidently enhanced PTEN and caspase-3 expressions while reducing Ki67 and vimentin expressions. Moreover, when combined with DOX, RES achieved a much more dramatic enhancive effect on PTEN and caspase-3, and displayed a more remarkable inhibitory effect on vimentin and Ki67 (Fig. 7b).

\section{Discussion}

Chemotherapy, which provides palliation of symptoms and improves survival and life quality, is the most effective treatment for patients with inoperable cancers. However, conventional DOX-based chemotherapy regimen has been criticized for a series of negative effects, including the development of drug resistance and the occurrence of Epithelial-mesenchymal transition (EMT) [21, 22].

EMT not only enhances the metastatic potentials of cancer but also participates in the development of chemo-resistance [23, 24]. EMT is the physiological or pathological conversion of epithelial cells to mesenchymal cells, in which cells undergo phenotypic changes including the loss of cell polarity and cell-cell adhesion, the acquisition of migratory and invasive properties, which are highly responsible for carcinoma progression. The EMT-induced stemness endows cancer cells with the ability to overexpress chemo-resistance related genes, leading to multiple drug resistance in cancer treatment [25]. A previous study detected DOX-induced EMT in BGC823 gastric cancer cells. Inhibition of $\beta$-catenin signaling could suppress DOX-induced EMT and cell migration [22]. Suppression of EMT through selective inhibition of $\beta$-catenin signaling could restore sensitivity to HER-2 targeted lapatinib in HER-2 positive gastric cancer cells SNU216 cells [26]. Very recently, an EMT lineage-tracing system was established to monitor reversible and transient EMT process in mice. Upon treatment with cancer chemotherapy drug cyclophosphamide, EMT cells were detected in the primary tumor and showed chemo-resistance owing to reduced proliferation, apoptotic tolerance and increased expression of chemoresistance-related genes. Theses EMT cells also contributed to recurrent lung metastasis formation after chemotherapy. These data suggested that EMT plays an important role in cancer drug resistance and contributes to metastasis after chemotherapy treatment [27]. In our study, we generated SGC7901/DOX cell line by long-term and incremental DOX treatment, which was characterized by the acquisition of drug resistance and enhancive migration (Fig. 2). And meanwhile, SGC7901/DOX cells displayed an apparent EMT potential for they were transformed into spindle-like shape, and expressed high level of mesenchymal cell markers including $\beta$-catenin and vimentin while losing epithelial cell adhesion molecule such as E-cadherin (Fig. 3).

EMT-mediated therapeutic resistance in solid tumors is regulated by many canonical signaling pathways, among which PI3K/Akt is of high interest. [28, 29] PI3K phosphorylates PIP2 into PIP3, which then phosphorylates Akt in turn. Akt gets activated by phosphorylation of its Ser473 residue and stimulates the mTOR complex 1 (mTORC1) by phosphorylating tuberous sclerosis complex2 (TSC2) and subsequently inhibiting TSC1/2 complex formation, which is a negative regulator of mTORC1. Further, the mTORC1 complex acts on RHEB (Ras homo$\log$ enriched in brain) to phosphorylate mTOR at Ser2448 and thus resulting in mTOR activation. Then mTOR regulates protein translation and cell growth by phosphorylating ribosomal S6 kinase (p70S6K) [30]. It has been reported that mTOR inhibitors decrease p70S6K and reverse resistance to DOX [31]. Another important substrate of Akt that initiates the mitochondrial apoptotic pathway is caspase-9, which is inactivated by Akt through the phosphorylation at Ser196 [32]. Caspase-9 inactivation then leads to the downregulation of caspase-3 and suppression of caspase-dependent apoptosis [33]. As other study shows, Akt activation induces cancer cell invasiveness partially through interaction with vimentin. The binding of Akt to vimentin enhances the ability of vimentin to induce motility and invasion while protecting vimentin from caspase-induced proteolysis [34]. Vimentin promotes cell invasiveness via the regulation of $E$-cadherin/ $\beta$-catenin complex. [35] Compared with E-cadherin and $\beta$-catenin, vimentin seemed to be a more specific and significant determinant for cancer metastasis [36, 37]. Moreover, Akt triggers DOX-induced EMT through Akt/GSK-3 $\beta / \beta$-catenin pathway. Nuclear translocation of $\beta$-catenin not only regulates EMT-associated proteins, which are responsible for cell migration, but also induces transcriptional upregulation of ZEB1, which in turn regulated DNA damage repair and DOX-resistance [38]. Recently, the promotion of Akt phosphorylation could facilitate EMT, resulting in tumor formation and invasion in AGS and MKN45 gastric cancer cell lines [39]. Given that Akt was activated in SGC7901/DOX cells, we are convinced that the upregulation of Akt signaling pathway best 


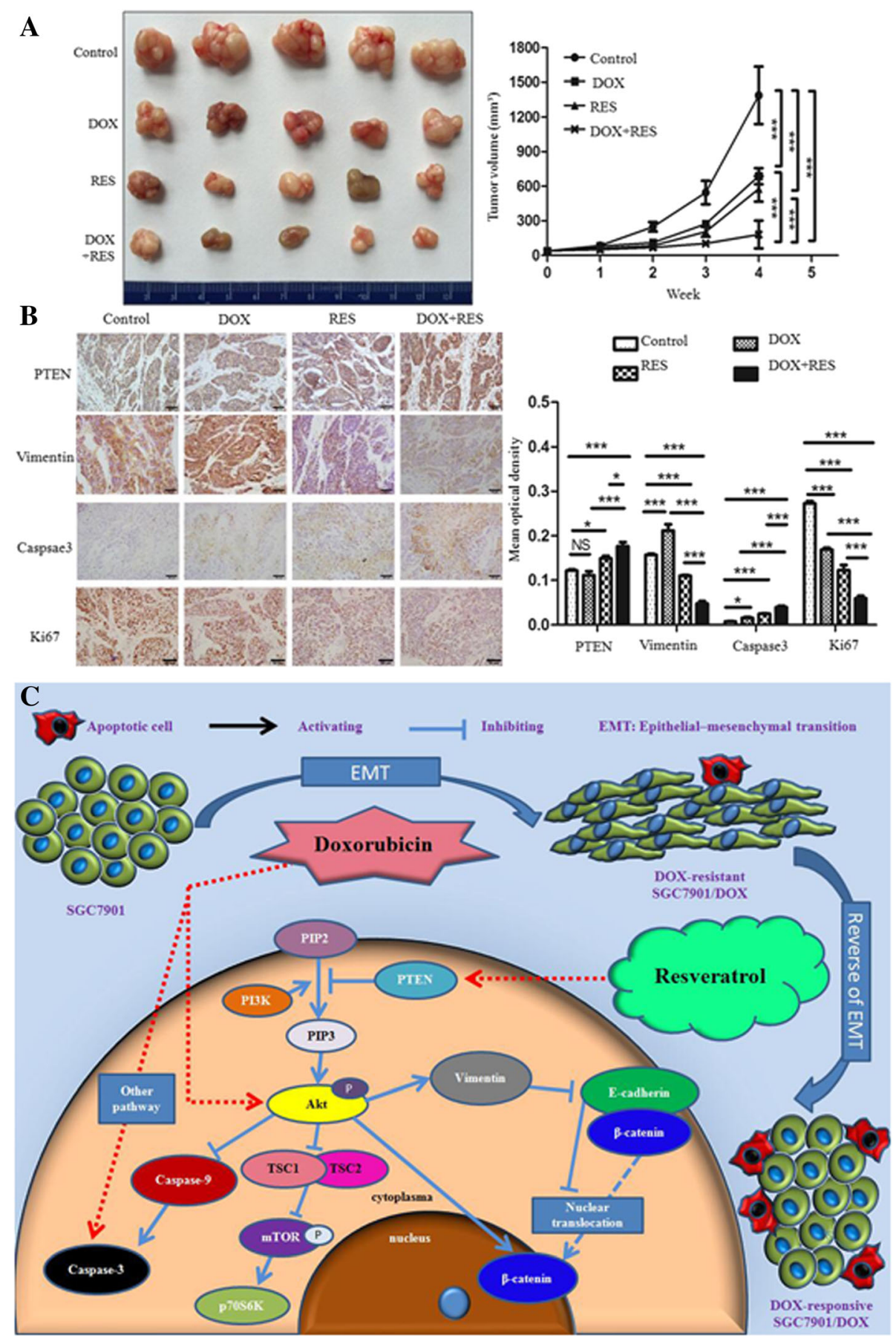

Fig. 7 Effect of DOX and RES on nude mice burdened with SGC7901/DOX xenograpfts. a Nude mice inoculated subcutaneously with SGC7901/ DOX cells were treated with DOX, RES or both for 4 weeks. At the end of the treatment period, mice were sacrificed and tumor specimens harvested. The tumor volume ( $V$ ) was determined by measuring the length (a) and width (b) with calipers every week and calculated using the formula: $V\left(\mathrm{~mm}^{3}\right)=1 / 2 a b^{2}$. Mean tumor volume for each treatment group is indicated. Results are represented as the mean \pm SD of 5 mice per group $\left(n=5,{ }^{* * *} p<0.001\right)$. b Tumor specimens were subjected to immunohistochemical staining for PTEN,Ki67, caspase3 and vimentin. Images were captured at 400x magnification. The Scale bar represents $50 \mu \mathrm{m}$. Mean density of each group (Integrated optical density/Area) was presented $\left(n=5,{ }^{* * *} p<0.001 ;{ }^{*} p<0.05\right.$;NS means not significant, $\left.p>0.05\right)$. c A hypothetical model illustrating that RES reverses DOX-induced EMT and DOX-resistance by modulating PTEN/Akt signaling pathway. This picture was designed by J.X. and Q.Z 
illustrates DOX-induced EMT, cell migration and drug resistance mentioned above. Even though activation of Akt signaling pathway was maintained by DOX treatment in SGC7901/DOX cells, caspase-3 mediated apoptosis was promoted by DOX in spite of caspase- 9 inactivation by Akt. Therefore, DOX could induce SGC7901/DOX cell apoptosis in an Akt-independent way.

To alleviate the adverse effects of DOX, we took note of RES, a well-known phytochemical with diverse health benefits, as a possible supplement for DOX treatment. RES demonstrated its valid potentials as a chemosensitizer for DOX in breast cancer cells [40]. In gastric cancer MGC803 cells, RES was able to induce cell cycle arrest by targeting PTEN. As a negative regulator of PI3K/Akt pathway which dephosphorylates PIP3, PTEN has been reported to reverse EMT-mediated drug resistance [41]. Consistent with our data, an early study revealed RES is able to suppress cell invasion and the expression of Snail and $\mathrm{N}$-cadherin and increase that of E-cadherin, which suggested that RES has an EMTinhibitory effect in SGC7901 cells [42]. We discovered that PTEN expression was enhanced by RES dominantly and dose-dependently in DOX-resistant SGC7901/DOX gastric cancer cells. Consequently, PI3K/Akt pathway was down-regulated, which activated caspase-3 dependent apoptosis, suppressed colony formation, and more importantly, inhibited EMT, leading to the suppression of cell migration and the reverse of DOX-resistance of SGC7901/DOX cells. Similar effects were also confirmed in SGC7901/DOX in vivo xenograpft tumor model.

\section{Conclusions}

Our study revealed that Akt aberrant activationmediated EMT is the key to the acquisition of DOXresistance in SGC7901 gastric cancer cells during longterm DOX treatment. RES could attenuate the adverse effects of DOX by activating PTEN and subsequently modulating Akt pathway activity, thus further promoting apoptosis and reversing EMT process. In conclusion, RES serves as a novel solution which can not only synergize DOX in inhibiting the tumor growth, but also reverse the DOX-resistance and prevent cell migration via the suppression of EMT in gastric cancer by modulating PTEN/Akt signaling pathway. The DOX-RES combined treatment provides a promising future for gastric cancer patients with metastasis and drug resistance tendency.

\section{Abbreviations}

ANOVA: Analysis of variance; CCK8: Cell counting kit-8; DOX: Doxorubicin; EMT: Epithelial-mesenchymal transition; mTOR: Mammalian target of rapamycin; PTEN: Phosphatase and tensin homolog deleted on chromosome ten; RES: Resveratrol

\section{Funding}

This work was supported by the National Natural Science Foundation of China (81272760\&81472712)

\section{Availability of data and materials}

Not applicable.

\section{Authors' contributions}

QZ and JX designed the research, JX and DL conducted the experiments, performed the data analysis and wrote the manuscript. GZ, YX, DY and $\mathrm{HN}$ contributed to the performing of the assay. All authors discussed the results and reviewed the manuscript. All authors read and approved the final manuscript.

\section{Competing interests}

The authors declare that they have no competing interests.

\section{Consent for publication}

Not applicable.

\section{Ethics approval}

All procedures regarding in vivo nude mice model are in accordance with the institutional guidelines of Guangdong Province and approved by the Experimental Animal Ethics Committee of Southern Medical University.

\section{Author details}

${ }^{1}$ Nanfang Hospital/First Clinical Medical School, Southern Medical University, Guangzhou 510515, China. ${ }^{2}$ Department of Pathology, School of Basic Medical Sciences, Southern Medical University, Guangzhou 510515, China. ${ }^{3}$ Department of Pathology, Nanfang Hospital, Southern Medical University, Guangzhou 510515, China.

Received: 20 November 2016 Accepted: 30 December 2016 Published online: 26 January 2017

\section{References}

1. Torre LA, Bray F, Siegel RL, Ferlay J, Lortet-Tieulent J, Jemal A. Global cancer statistics, 2012. CA Cancer J Clin. 2015;65:87-108.

2. Thompson GB, van Heerden JA, Sarr MG. Adenocarcinoma of the stomach: are we making progress? Lancet. 1993;342:713-8.

3. Greenlee RT, Murray T, Bolden S, Wingo PA. Cancer statistics, 2000. CA Cancer J Clin. 2000;50:7-33.

4. D'Angelica M, Gonen M, Brennan MF, Turnbull AD, Bains M, Karpeh MS. Patterns of initial recurrence in completely resected gastric adenocarcinoma. Ann Surg. 2004;240:808-16.

5. Glimelius B, Hoffman K, Haglund U, Nyren O, Sjoden PO. Initial or delayed chemotherapy with best supportive care in advanced gastric cancer. Ann Oncol. 1994:5:189-90.

6. Pyrhonen S, Kuitunen T, Nyandoto P, Kouri M. Randomised comparison of fluorouracil, epidoxorubicin and methotrexate (FEMTX) plus supportive care with supportive care alone in patients with non-resectable gastric cancer. $\mathrm{Br}$ J Cancer. 1995;71:587-91.

7. MacDonald JS, Schein PS, Woolley PV, Smythe T, Ueno W, Hoth D, Smith F, Boiron M, Gisselbrecht C, Brunet R, Lagarde C. 5-Fluorouracil, doxorubicin, and mitomycin (FAM) combination chemotherapy for advanced gastric cancer. Ann Intern Med. 1980;93:533-6.

8. Chang HM, Jung KH, Kim TY, Kim WS, Yang HK, Lee KU, Choe KJ, Heo DS, Bang YJ, Kim NK. A phase III randomized trial of 5-fluorouracil, doxorubicin, and mitomycin $C$ versus 5 -fluorouracil and mitomycin $C$ versus 5-fluorouracil alone in curatively resected gastric cancer. Ann Oncol. 2002;13:1779-85.

9. Macdonald JS, Fleming TR, Peterson RF, Berenberg JL, McClure S, Chapman RA, Eyre HJ, Solanki D, Cruz Jr AB, Gagliano R, et al. Adjuvant chemotherapy with 5-FU, adriamycin, and mitomycin-C (FAM) versus surgery alone for patients with locally advanced gastric adenocarcinoma: A Southwest Oncology Group study. Ann Surg Oncol. 1995;2:488-94.

10. Lise M, Nitti D, Marchet A, Sahmoud T, Buyse M, Duez N, Fiorentino M, Dos Santos JG, Labianca R, Rougier P, et al. Final results of a phase III clinical trial of adjuvant chemotherapy with the modified fluorouracil, doxorubicin, and mitomycin regimen in resectable gastric cancer. J Clin Oncol. 1995;13:2757-63. 
11. Zhang $Y W$, Zhang YL, Pan H, Wei FX, Zhang YC, Shao Y, Han W, Liu HP, Wang ZY, Yang SH. Chemotherapy for patients with gastric cancer after complete resection: a network meta-analysis. World J Gastroenterol. 2014;20:584-92

12. Morikawa Y, Kezuka C, Endo S, Ikari A, Soda M, Yamamura K, Toyooka N, ElKabbani O, Hara A, Matsunaga T. Acquisition of doxorubicin resistance facilitates migrating and invasive potentials of gastric cancer MKN45 cells through up-regulating aldo-keto reductase 1B10. Chem Biol Interact. 2015:230:30-9

13. Vinod BS, Maliekal TT, Anto RJ. Phytochemicals as chemosensitizers: from molecular mechanism to clinical significance. Antioxid Redox Signal. 2013; 18:1307-48

14. Novelle MG, Wahl D, Dieguez C, Bernier M, de Cabo R. Resveratrol supplementation: where are we now and where should we go? Ageing Res Rev. 2015;21:1-15.

15. Signorelli $P$, Ghidoni R. Resveratrol as an anticancer nutrient: molecular basis, open questions and promises. J Nutr Biochem. 2005;16:449-66.

16. Park EJ, Pezzuto JM. The pharmacology of resveratrol in animals and humans. Biochim Biophys Acta. 2015;1852:1071-113.

17. Kim TH, Shin YJ, Won AJ, Lee BM, Choi WS, Jung JH, Chung HY, Kim HS. Resveratrol enhances chemosensitivity of doxorubicin in multidrug-resistant human breast cancer cells via increased cellular influx of doxorubicin. Biochim Biophys Acta. 1840;2014:615-25.

18. Kweon SH, Song JH, Kim TS. Resveratrol-mediated reversal of doxorubicin resistance in acute myeloid leukemia cells via downregulation of MRP1 expression. Biochem Biophys Res Commun. 2010;395:104-10.

19. Wang CJ, Zhou ZG, Holmqvist A, Zhang H, Li Y, Adell G, Sun XF. Survivin expression quantified by Image Pro-Plus compared with visual assessment. Appl Immunohistochem Mol Morphol. 2009;17:530-5.

20. Xavier LL, Viola GG, Ferraz AC, Da Cunha C, Deonizio JM, Netto CA, Achaval M. A simple and fast densitometric method for the analysis of tyrosine hydroxylase immunoreactivity in the substantia nigra pars compacta and in the ventral tegmental area. Brain Res Brain Res Protoc. 2005;16:58-64.

21. Broxterman HJ, Gotink KJ, Verheul HM. Understanding the causes of multidrug resistance in cancer: a comparison of doxorubicin and sunitinib. Drug Resist Updat. 2009;12:114-26.

22. Han R, Xiong J, Xiao R, Altaf E, Wang J, Liu Y, Xu H, Ding Q, Zhang Q. Activation of beta-catenin signaling is critical for doxorubicin-induced epithelial-mesenchymal transition in BGC-823 gastric cancer cell line. Tumour Biol. 2013;34:277-84.

23. Thiery JP, Acloque H, Huang RY, Nieto MA. Epithelial-mesenchymal transitions in development and disease. Cell. 2009;139:871-90.

24. Bharti R, Dey G, Mandal M. Cancer development, chemoresistance, epithelial to mesenchymal transition and stem cells: A snapshot of IL-6 mediated involvement. Cancer Lett. 2016;375:51-61.

25. Xu J, Lamouille S, Derynck R. TGF-beta-induced epithelial to mesenchymal transition. Cell Res. 2009;19:156-72.

26. Lee YY, Kim HP, Kang MJ, Cho BK, Han SW, Kim TY, Yi EC. Phosphoproteomic analysis identifies activated MET-axis PI3K/AKT and MAPK/ERK in lapatinib-resistant cancer cell line. Exp Mol Med. 2013;45:e64.

27. Fischer KR, Durrans A, Lee S, Sheng J, Li F, Wong ST, Choi H, El Rayes T, Ryu $\mathrm{S}$, Troeger J, et al. Epithelial-to-mesenchymal transition is not required for lung metastasis but contributes to chemoresistance. Nature. 2015;527:472-6.

28. Smith BN, Bhowmick NA. Role of EMT in Metastasis and Therapy Resistance. J Clin Med. 2016:5:17.

29. van der Wekken AJ, Saber A, Hiltermann TJ, Kok K, van den Berg A, Groen HJ. Resistance mechanisms after tyrosine kinase inhibitors afatinib and crizotinib in non-small cell lung cancer, a review of the literature. Crit Rev Oncol Hematol. 2016;100:107-16.

30. Singh SS, Yap WN, Arfuso F, Kar S, Wang C, Cai W, Dharmarajan AM, Sethi G, Kumar AP. Targeting the PI3K/Akt signaling pathway in gastric carcinoma: a reality for personalized medicine? World J Gastroenterol. 2015;21:12261-73.

31. Grunwald V, DeGraffenried L, Russel D, Friedrichs WE, Ray RB, Hidalgo M. Inhibitors of mTOR reverse doxorubicin resistance conferred by PTEN status in prostate cancer cells. Cancer Res. 2002;62:6141-5.

32. Sangawa A, Shintani M, Yamao N, Kamoshida S. Phosphorylation status of Akt and caspase-9 in gastric and colorectal carcinomas. Int J Clin Exp Pathol. 2014;7:3312-7

33. Mohammad RM, Muqbil I, Lowe L, Yedjou C, Hsu HY, Lin LT, Siegelin MD, Fimognari C, Kumar NB, Dou QP, et al. Broad targeting of resistance to apoptosis in cancer. Semin Cancer Biol. 2015;35(Suppl):S78-103. doi:10.1016/ j.semcancer.2015.03.001.

34. Zhu QS, Rosenblatt K, Huang KL, Lahat G, Brobey R, Bolshakov S, Nguyen T, Ding Z, Belousov R, Bill K, et al. Vimentin is a novel AKT1 target mediating motility and invasion. Oncogene. 2011;30:457-70.

35. Wei J, Xu G, Wu M, Zhang Y, Li Q, Liu P, Zhu T, Song A, Zhao L, Han Z, et al. Overexpression of vimentin contributes to prostate cancer invasion and metastasis via src regulation. Anticancer Res. 2008;28:327-34.

36. Balasundaram P, Singh MK, Dinda AK, Thakar A, Yadav R. Study of betacatenin, E-cadherin and vimentin in oral squamous cell carcinoma with and without lymph node metastases. Diagn Pathol. 2014;9:145.

37. Otsuki S, Inokuchi M, Enjoji M, Ishikawa T, Takagi Y, Kato K, Yamada H, Kojima K, Sugihara K. Vimentin expression is associated with decreased survival in gastric cancer. Oncol Rep. 2011;25:1235-42.

38. Wang $C$, Jin $H$, Wang $N$, Fan $S$, Wang $Y$, Zhang $Y$, Wei L, Tao X, Gu D, Zhao $F$, et al. Gas6/Axl axis contributes to chemoresistance and metastasis in breast cancer through Akt/GSK-3beta/beta-catenin signaling. Theranostics. 2016;6:1205-19.

39. Wang YG, Xu L, Jia RR, Wu Q, Wang T, Wei J, Ma JL, Shi M, Li ZS. DDR2 Induces Gastric Cancer Cell Activities via Activating mTORC2 Signaling and Is Associated with Clinicopathological Characteristics of Gastric Cancer. Dig Dis Sci. 2016:61(8):2272-83. doi:10.1007/s10620-016-4116-3.

40. Rai G, Mishra S, Suman S, Shukla Y. Resveratrol improves the anticancer effects of doxorubicin in vitro and in vivo models: a mechanistic insight. Phytomedicine. 2016;23:233-42.

41. Jing $X$, Cheng W, Wang S, Li P, He L. Resveratrol induces cell cycle arrest in human gastric cancer MGC803 cells via the PTEN-regulated PI3KAAkt signaling pathway. Oncol Rep. 2016;35:472-8.

42. Bai Y, Lu H, Wu C, Liang Y, Wang S, Lin C, Chen B, Xia P. Resveratrol inhibits epithelial-mesenchymal transition and renal fibrosis by antagonizing the hedgehog signaling pathway. Biochem Pharmacol. 2014;92:484-93.

\section{Submit your next manuscript to BioMed Central and we will help you at every step:}

- We accept pre-submission inquiries

- Our selector tool helps you to find the most relevant journal

- We provide round the clock customer support

- Convenient online submission

- Thorough peer review

- Inclusion in PubMed and all major indexing services

- Maximum visibility for your research

Submit your manuscript at www.biomedcentral.com/submit
) Biomed Central 